\title{
DEBATENDO OS TEMAS AGROINDUSTRIA E AGROTURISMO POR MEIO DE SEQUÊNCIA DIDÁTICA DE GEOGRAFIA: UMA ABORDAGEM SOCIOCULTURAL NO ENSINO MÉDIO
}

\author{
Elaine Cristina Rossi ${ }^{1}$, Eduardo Augusto Moscon Oliveira ${ }^{2}$ \\ Sidnei Quezada Meireles Leite ${ }^{3}$
}

\author{
Programa de Pós-graduação em Educação em Ciências e Matemática \\ Instituto Federal do Espírito Santo - Campus Vitória \\ Avenida Vitória, 1729 - Jucutuquara, Vitória, Espírito Santo. CEP 29040780.
}

\begin{abstract}
RESUMO
Uma sequência didática abordando os temas agroindústria e agroturismo, perpassando pelas disciplinas de História, Geografia e Sociologia, foi planejada e aplicada em turmas de $2^{\circ}$ e $3^{\circ}$ anos de uma escola pública de Ensino Médio, localizada em Viana-ES. A SD foi planejada com base em Demétrio Delizoicov, José Angotti e Martha Pernambuco usando os Três Momentos Pedagógicos: problematização, organização do conhecimento e aplicação do conhecimento. A organização da sequência didática permitiu abordar questões científicas e socioambientais articuladas aos conteúdos programáticos de geografia do Ensino Médio.
\end{abstract}

Palavras-chave: sequência didática. ensino de geografia. três momentos pedagógicos. educação científica.

\section{ABSTRACT}

A teaching sequence addressing agribusiness and agritourism themes, passing by the disciplines of History, Geography and Sociology, has been planned and implemented in groups of 2 and 3 years of a public secondary school located in Viana of Espírito Santo State of Brazil. The SD was planned based on Demetrius Delizoicov, José Angotti and Martha Pernambuco using the Three Pedagogical Moments: questioning, organization of knowledge and application of knowledge. The organization of the didactic approach articulated sequence allowed the geography syllabus of high school science and environmental issues.

Keywords: teaching sequence. teaching geography. three pedagogical moments. science education.

\footnotetext{
1 Professora de Geografia da Rede Estadual de Educação Básica do Espírito Santo, Mestre em Educação em Ciências e Matemática - E-mail: elainecristinarossi@hotmail.com

2 Professor de Ensino de História da Universidade Federal do Espírito Santo, D.Ed. - Docente do Programa de Pós-graduação em Educação em Ciências e Matemática do Ifes. E-mail: edmoscon@gmail.com

3 Professor de Educação em Ciências e Química do Instituto Federal do Espírito Santo, D.Sc. - Docente do Programa de Pós-graduação em Educação em Ciências e Matemática do Ifes. E-mail: squezada@ifes.edu.br
} 


\section{\begin{tabular}{l|l} 
Ensino de Ciências e Matemática & 4
\end{tabular} \\ Sequência didática para debater os temas agroindústria e agroturismo}

\section{INTRODUÇÃo}

Para analisar a prática educativa Zabala (1998) propõe as sequências de atividades ou sequências didáticas como um “conjunto de atividades ordenadas, estruturadas e articuladas para a realização de certos objetivos educacionais, que têm um princípio e um fim conhecidos tanto pelos professores como pelos alunos" (p. 18). Nesta proposta de trabalho aparecem para os educandos diferentes oportunidades de aprender diversos conteúdos de maneira interdisciplinar, e para os professores, uma diversidade de meios para captar os processos de construção que eles edificam, de possibilidades de neles incidir e avaliar. A sequência didática engloba os conteúdos conceituais, procedimentais e atitudinais.

Uma forma de determinar os objetivos da educação é analisar as capacidades que se pretende desenvolver nos educandos. Contudo, existem diferentes formas de classificar as capacidades do ser humano. Zabala (1998) utiliza a classificação proposta por Coll - capacidades cognitivas ou intelectuais, motoras, de equilíbrio e autonomia pessoal (afetivas), de relação interpessoal e de inserção e atuação social. Diretamente relacionados aos objetivos da educação estão os conteúdos de aprendizagem. Coll (1986, apud ZABALA, 1998) os agrupa em conteúdos conceituais - fatos, conceitos e princípios - procedimentais - procedimentos, técnicas e métodos - e atitudinais - valores, atitudes e normas.

A aprendizagem baseada em problemas (ABP) é uma metodologia que ensina os alunos a aprenderem com autonomia, o papel do aluno destaca-se por apresentar: participação ativa nas discussões realizadas, contribuir com seus conhecimentos e experiências prévias em todas as reuniões, colaborar com os conhecimentos adquiridos, justificando-os com as referências bibliográficas pesquisadas, ou seja, devem ajudar o grupo a solucionar o problema. Ao revelar por si só, com um pequeno auxílio do professor, o que era desconhecido, o indivíduo conquista melhores condições de aprender.

[...] a ABP, assim como a problematização, "são ferramentas utilizadas para favorecer ao estudante a obtenção de conhecimentos, bem como habilidades e atitudes". Segundo Teixeira, "é uma estratégia pedagógica e um método de desenvolvimento curricular, que permite desenvolver simultaneamente estratégias para resolução de problemas, bases de conhecimentos disciplinares e competências". Segundo o autor, a principal característica 
dessa metodologia é o fato de ser centrada no aluno, desenvolver-se em pequenos grupos tutoriais, apresentar problemas em um determinado contexto, ser um processo ativo, cooperativo, integrado e interdisciplinar. A ABP visa, dentre outras coisas, a estimular no aluno a capacidade de aprender a aprender, de trabalhar em equipe, de ouvir outras opiniões, mesmo que contrárias às suas e induz o aluno a assumir um papel ativo e responsável pelo seu aprendizado. Objetiva também conscientizar o aluno do que ele sabe e do que precisa aprender, motivando-o a ir buscar as informações relevantes (MALHEIRO e DINIZ, 2008, p. 2).

Neste artigo, partimos da premissa de utilizar a metodologia de ABP como parte integrante dos momentos da sequencia didática. Assim, ao realizar uma abordagem baseada em ABP, acreditamos que o aluno será levado a confrontar o conhecimento prévio construído ao longo da história de vida dele, com o conhecimento que é apresentado nos diferentes momentos da sequencia didática, propiciando um desenvolvimento mais integral por meio da aquisição de conceitos, procedimentos e atitudes. Os educando do Ensino Médio precisam de mais incentivo à pesquisa do que vem sendo oferecido nos últimos anos. Como nos ensina Paulo Freire:

não há ensino sem pesquisa e pesquisa sem ensino. Esses que-fazeres se encontram um no corpo do outro. Enquanto ensino continuo buscando, reprocurando. Ensino porque busco, porque indago e me indago. Pesquiso para constatar, constatando, intervenho, intervindo educo e me educo. Pesquiso para conhecer o que ainda não conheço e comunicar ou anunciar a novidade (FREIRE, 1996, p.29).

Para incentivar a pesquisa e favorecer ao estudante a obtenção de conhecimentos, bem como habilidades e atitudes, propomos a utilização de uma sequência didática interdisciplinar baseada na aprendizagem baseada em problemas para abordarmos dois temas referentes ao arcabouço da Geografia. A constituição de um objeto simultaneamente interdisciplinar, polidisciplinar e transdisciplinar permite criar a troca, a cooperação e a policompetência (MORIN, 2005, p.45). A complexidade dos saberes e das metodologias que permeiam o mundo contemporâneo requerem profissionais multifuncionais, com competências e habilidades para estabelecer as conexões entre o conhecimento empírico e o conhecimento científico. Morin, afirma que

[...] o desafio da complexidade se intensifica no mundo contemporâneo já que nos encontramos numa época de mundialização, que prefiro chamar de era planetária. Isso significa que todos os problemas fundamentais que se colocam num contexto francês ou europeu o ultrapassam, pois decorrem cada um a seu 
modo, dos processos mundiais. Os problemas mundiais agem sobre os processos mundiais. Responder a este desafio contextualizando-o em escala mundial, quer dizer globalizando-o, tornou-se algo absolutamente essencial, apesar de sua extrema dificuldade (MORIN, 2005, p.64).

O objetivo deste artigo foi analisar uma sequencia didática de geografia mediada pelos temas agroindústria e agroturismo, realizados nas turmas de $2^{\circ}$ e $3^{\circ}$ ano do Ensino Médio. A sequencia didática foi planejada com base nos Três Momentos Pedagógicos (TMP) de Delizoiv, Angotti e Pernambuco (2003), articulada com a abordagem de Aprendizagem Baseada em Problemas (ABP).

\section{PROCEDIMENTOS METODOLÓGICOS}

A elaboração de uma SD interdisciplinar só foi possível após o estabelecimento de um dia de planejamento por área de conhecimento, nas escolas da rede estadual de educação no estado do Espírito Santo. A SD foi aplicada aos educandos dos $2^{\circ}$ e $3^{\circ}$ anos da Escola Estadual de Ensino Médio Irmã Dulce Lopes Ponte, localizada em Marcílio de Noronha/Viana. Foram 194 alunos dos turnos matutino e vespertino, sendo realizadas sete aulas de campo na Fazenda Rico Caipira, localizada em Vila Velha/ES, durante todo mês de Junho de 2012. Apresentamos nos Quadros 1 e 2 como foi organizada a SD na disciplina de Geografia.

Quadro1. Problematização e objetivos da sequencia didática de Geografia para debater os temas Agroindústria e Agroturismo.

\begin{tabular}{|l|l|}
\hline Título: & Agroindústria e Agroturismo \\
\hline Público Alvo: & Alunos dos 2o e 3o anos do Ensino Médio Regular \\
\hline Problematização: & \multicolumn{1}{|c|}{$\begin{array}{c}\text { “O que vamos almoçar hoje?” } \\
\text { Como se desenvolvem as atividades de agroturismo e agroindústria na Região } \\
\text { Metropolitana da Grande Vitória? }\end{array}$} \\
\hline Objetivos Gerais: & $\begin{array}{l}\text { Identificar as atividades econômicas realizadas nas áreas rurais } \\
\text { (Mundo/Brasil/Espírito Santo) ao longo do tempo. } \\
\text { Reconhecer a dinâmica espacial decorrente dos fluxos migratórios entre a cidade e o } \\
\text { campo. } \\
\text { Demonstrar a organização e o funcionamento de uma propriedade agrícola que } \\
\text { desenvolve a agroindústria e o agroturismo. }\end{array}$ \\
\hline
\end{tabular}


Quadro 2. Etapas da Sequencia Didática de Geografia para debater os temas Agroindústria e Agroturismo.

\begin{tabular}{|c|c|c|c|}
\hline AULA & OBJETIVOS ESPECÍFICOS & CONTEÚDOS & DINÂMICAS \\
\hline 01 & $\begin{array}{c}\text { Relacionar os } \\
\text { conhecimentos prévios } \\
\text { dos educandos sobre as } \\
\text { áreas rurais com as suas } \\
\text { aplicações na vida urbana. }\end{array}$ & $\begin{array}{ll}\text { - } & \text { Técnicas de cultivo; } \\
\text { - } & \text { Tipos de produção agrícola (familiar e } \\
\text { agronegócio). } \\
\text { - } \quad \text { Produtos industrializados. } \\
\text { - } \quad \text { Produtos agrícolas. } \\
\text { - } \quad \text { Agronegócios. } \\
\text { Logística de distribuição dos alimentos } \\
\text { (supermercados, CEASA, feiras livres, } \\
\text { etc.) }\end{array}$ & $\begin{array}{l}\text { Iniciar a aula com a seguinte pergunta: } 0 \text { que } \\
\text { vamos almoçar hoje? } \\
\text { Discutir os cardápios e as suas possíveis } \\
\text { origens. } \\
\text { Relacionar no quadro uma lista de produtos } \\
\text { industrializados e outra de produtos agrícolas. } \\
\text { Solicitar uma pesquisa sobre a origem dos } \\
\text { agrícolas. }\end{array}$ \\
\hline 02 & $\begin{array}{l}\text { Organizar o conhecimento } \\
\text { adquirido sobre o assunto. }\end{array}$ & $\begin{array}{ll}\text { - } & \text { Agroindústrias. } \\
\text { - } & \text { Exodo Rural. } \\
\text { - } & \text { Transporte. } \\
\text { - } & \text { Transgênicos. } \\
\text { - } & \text { Melhoramento genético. } \\
\text { - } & \text { Agrotóxico. } \\
\text { - } & \text { Modernização agropecuária. } \\
\text { - } & \text { Natureza e tecnologia. } \\
\text { - } & \text { Organização do espaço. } \\
\text { - } & \text { Biotecnologia. } \\
\text { - } & \text { Produtos orgânicos. }\end{array}$ & $\begin{array}{l}\text { Apresentar e comentar os resultados das } \\
\text { pesquisas; relacionar no quadro os conceitos } \\
\text { mais importantes apontados pelos alunos. } \\
\text { Dividir a turma em grupos e cada grupo } \\
\text { produzir um texto com os resultados das } \\
\text { pesquisas. Neste texto devem aparecer os } \\
\text { conceitos relacionados no quadro. } \\
\text { Ler os textos do livro didático que possam } \\
\text { apoiar na elaboração do texto. }\end{array}$ \\
\hline 03 & $\begin{array}{l}\text { Sintetizar os } \\
\text { conhecimentos sobre } \\
\text { agroindústria, produção } \\
\text { agrícola e agropecuária. }\end{array}$ & $\begin{array}{l}\text { - Sistematização dos conteúdos adquiridos. } \\
\text { - Orientações sobre a aula de campo } \\
\text { (objetivos, custos, procedimentos, forma de } \\
\text { avaliação) }\end{array}$ & $\begin{array}{l}\text { Apresentação dos textos produzidos pelos } \\
\text { grupos para o restante da turma. } \\
\text { Discussão dos pontos que mais se repetem nos } \\
\text { textos. }\end{array}$ \\
\hline 04 & $\begin{array}{c}\text { Apresentar uma } \\
\text { propriedade que } \\
\text { desenvolve atividades de } \\
\text { agroturismo e } \\
\text { agroindústria na RMGV. }\end{array}$ & $\begin{array}{ll}\text { - } & \text { Inseminação artificial. } \\
\text { - } & \text { Ordenha mecânica. } \\
\text { - } & \text { Adubação química e orgânica. } \\
\text { - } & \text { Produção leiteira. } \\
\text { - } & \text { Agroindústria (laticínios) } \\
\text { - } & \text { Agroturismo. }\end{array}$ & $\begin{array}{l}\text { Aula de campo na Fazenda Rico Caipira em } \\
\text { Vila Velha. } \\
\text { Acompanhar todos os processos produtivos da } \\
\text { criação de gado leiteiro. } \\
\text { Conhecer o processo produtivo do laticínio. } \\
\text { Lanchar e desfrutar das atividades } \\
\text { proporcionadas pelo agroturismo. }\end{array}$ \\
\hline 05 & $\begin{array}{l}\text { Entregar os relatórios da } \\
\text { aula de campo. }\end{array}$ & $\begin{array}{l}\text { - } \\
\text { - }\end{array}$ & $\begin{array}{l}\text { Oportunizar que os alunos vejam os relatórios } \\
\text { dos colegas e comentem os pontos mais } \\
\text { relevantes. }\end{array}$ \\
\hline
\end{tabular}

Na elaboração e aplicação dessa sequência didática utilizamos a proposta de Delizoicov et al. (2009), com os três momentos pedagógicos (TMP), que prevê um momento inicial de problematização, a organização do conhecimento e a aplicação do conhecimento. A problematização continua durante todas as etapas de desenvolvimento da mesma, uma vez que a SD se dá por meio da ABP. A primeira atividade é uma problematização que nos leva a refletir: 0 que vamos almoçar hoje? De onde vêm os alimentos? Como eles são produzidos?

A avaliação das etapas de problematização e aula teórico-prática foi realizada por meio de produção de um texto em grupo a partir de uma pesquisa sobre as atividades agrícolas e 
agroindustriais que fornecem os alimentos que utilizamos em nossa alimentação no dia a dia. Também foi realizado uma produção de relatório fotográfico, em duplas, sobre a aula de campo na Fazenda Rico Caipira. Para realização das aulas teórico-práticas de Geografia, utilizamos como referencial teórico o livro Lydia Terra; ARAÚJO, Regina; GUIMARÃES, Raul Borges. Conexões: Estudos de Geografia Geral e do Brasil. 1a Ed. - São Paulo: Moderna, 2010. Volumes 2 e 3.

\section{RESULTADOS E DISCUSSÃO}

Para articular esse conhecimento que Morin chama de planetário ou globalizado, articulamos as disciplinas da área de conhecimento das Ciências Humanas: História, Geografia e Sociologia para elaborar uma sequência didática e pesquisar as temáticas: agroindústrias e agroturismo. O mapa conceitual (Quadro 3) apresenta de forma sucinta as possibilidades de articulação de conteúdos programáticos a partir da abordagem temática, com a metodologia proposta.

Quadro 3. Mapa Conceitual da atividade pedagógica.

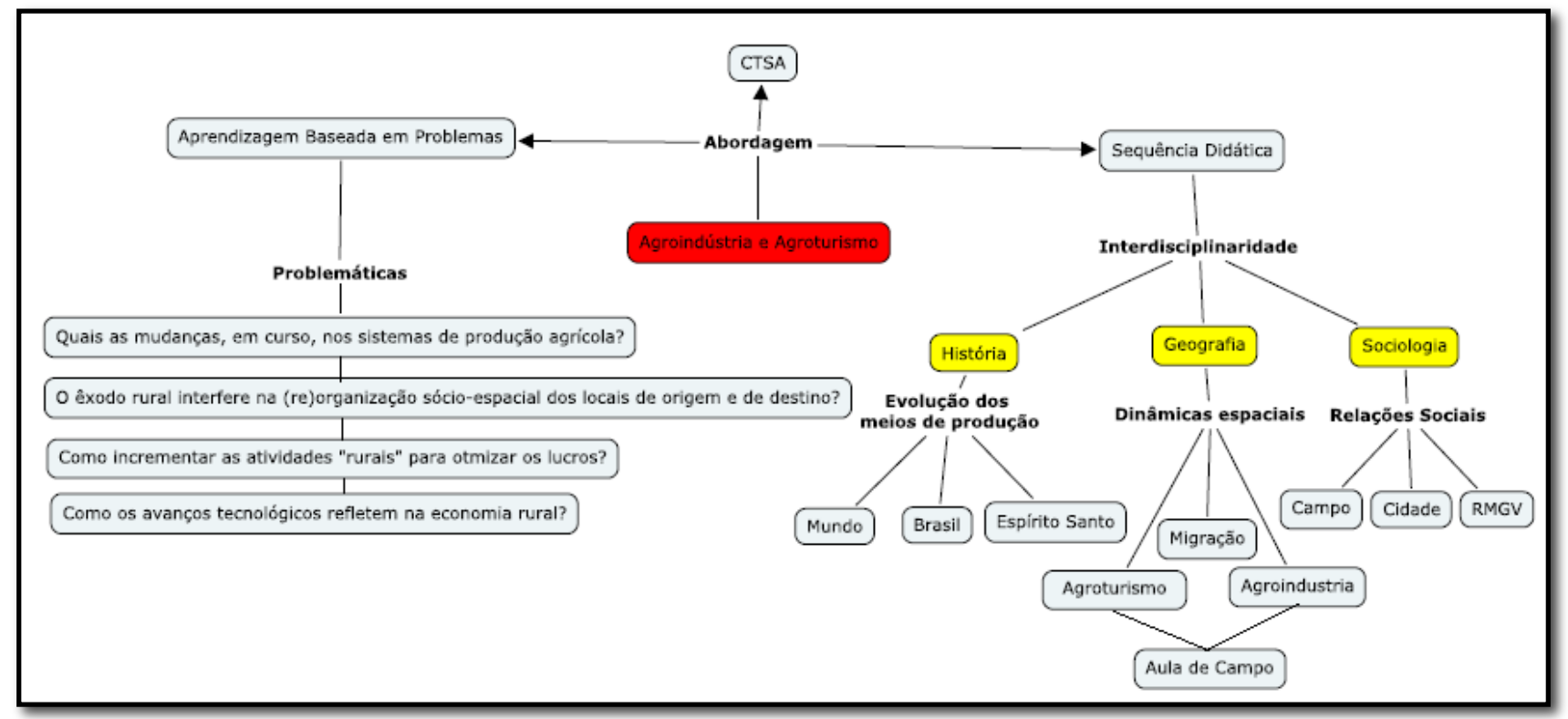


O planejamento e a realização desta sequência didática ocorreram de forma interdisciplinar, mas apresentaremos, neste artigo, o tratamento do tema dentro da disciplina de Geografia, a fim de apresentar alguns resultados obtidos principalmente por meio da pesquisa e da aula de campo, pois, acreditamos que

Uma das etapas importantes do estudo do meio é o trabalho de campo - a saída da escola já permite outro modo de olhar. 0 aluno pode, se bem orientado, utilizar todos os seus sentidos para conhecer melhor certo meio, usar todos os recursos de observação e registros e cotejar as falas de pessoas de diferentes idades e profissões (PONTUSCHKA, PAGANELLI, CACETE, 2009, p.174).

Paulo Freire (1996) orienta que ensinar exige respeito aos saberes dos educandos, então, inicialmente todas as respostas são consideradas e anotadas no quadro. Após esse momento inicial, são propostas pesquisas sobre o assunto e a exposição dos resultados para toda turma, ensinar exige criticidade. A elaboração do texto em grupo permite a sistematização dos conhecimentos apreendidos e a troca de conhecimentos. 0 livro didático tem a função de apoio ao processo educativo.

As principais características da metodologia de ABP são: o fato de ser centrada no aluno, desenvolver-se em pequenos grupos tutoriais, apresentar problemas em um determinado contexto, ser um processo ativo, cooperativo, integrado e interdisciplinar (MALHEIRO, DINIZ, 2007, p.2).

Por meio das aulas a campo, os alunos realizaram observações diretas, contribuindo para a alfabetização científica, na medida em que permitiu, de modo sistemático, mediar o uso dos conhecimentos para melhor compreender as situações reais. Os alunos acabam utilizando todos os sentidos e não apenas a observação visual, pois “[...] o contato com ambientes, seres vivos, áreas em construção, máquinas em funcionamento, possibilita observações de tamanho, formas, comportamentos e outros aspectos dinâmicos, dificilmente proporcionados pelas observações indiretas" (Parâmetros curriculares nacionais: Ciências Naturais. Brasília: MEC/SEF. 1997, p. 122). 
0 estudo do meio é uma metodologia de ensino interdisciplinar que pretende desvendar a complexidade de um espaço determinado extremamente dinâmico e em constante transformação, cuja totalidade dificilmente uma disciplina escolar isolada pode dar conta de compreender. 0 estudo do meio, além de ser interdisciplinar, permite que aluno e professor se embrenhem num processo de pesquisa. Mais importante do que dar conta de um rol de conteúdos extremamente longo, sem relação com a vivência do aluno e com aquilo que ele já detém como conhecimento primeiro, é saber como esses conteúdos são produzidos (PONTUSCHKA, PAGANELLI, CACETE, 2009, p.173).

Os 194 educandos que tiveram a oportunidade de aprender com a Claudete e o Ricardo, proprietários da Fazenda Rico Caipira, como funciona o passo a passo de um fazenda leiteira que produz laticínios (queijo, iogurte e manteiga) e desenvolve o agroturismo tiveram momentos de aprendizagem e descontração que contribuem para uma aprendizagem significativa. As Figuras 1, 2, 3 e 4 apresentam alguns momentos de interação com o meio e os conteúdos agroindústria e agroturismo na Fazenda Rico Caipira:

Figura 1: Pecuária Leiteira: explicação sobre o processo de inseminação artificial/recria de bezerras/piquetes rotacionais de pastagem/adubação química e orgânica das pastagens/cadeia alimentar (capim-vaca-carrapatos-garças)/centro de manejo (ração-salbebedouro).
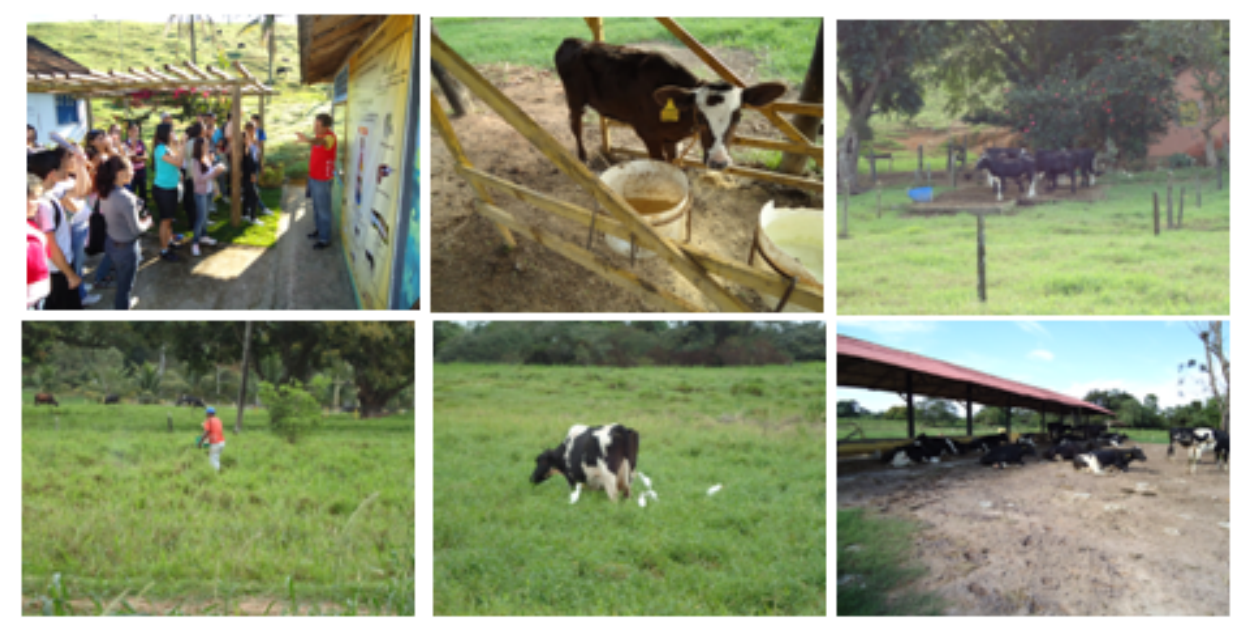

Fonte: Fotografias do arquivo pessoal dos autores. 
Figura 2: Produção de Laticínios: ordenha mecânica com música clássica/complementação alimentar durante a ordenha/tanque de armazenamento do leite/recepção do leite no laticínio/produção de queijos e manteiga/produção de iogurtes.
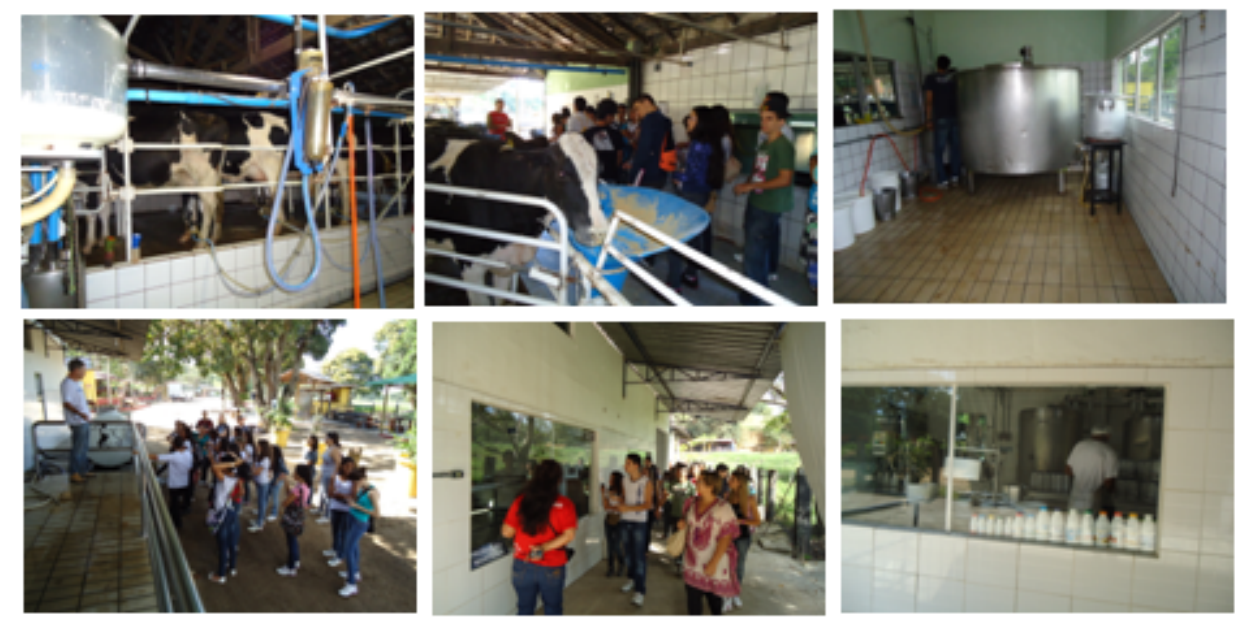

Fonte: Fotografias do arquivo pessoal dos autores.

Figura 3: Fazendinha: galinhas de várias espécies/pavão/pônei/coelho/avestruz e peru.

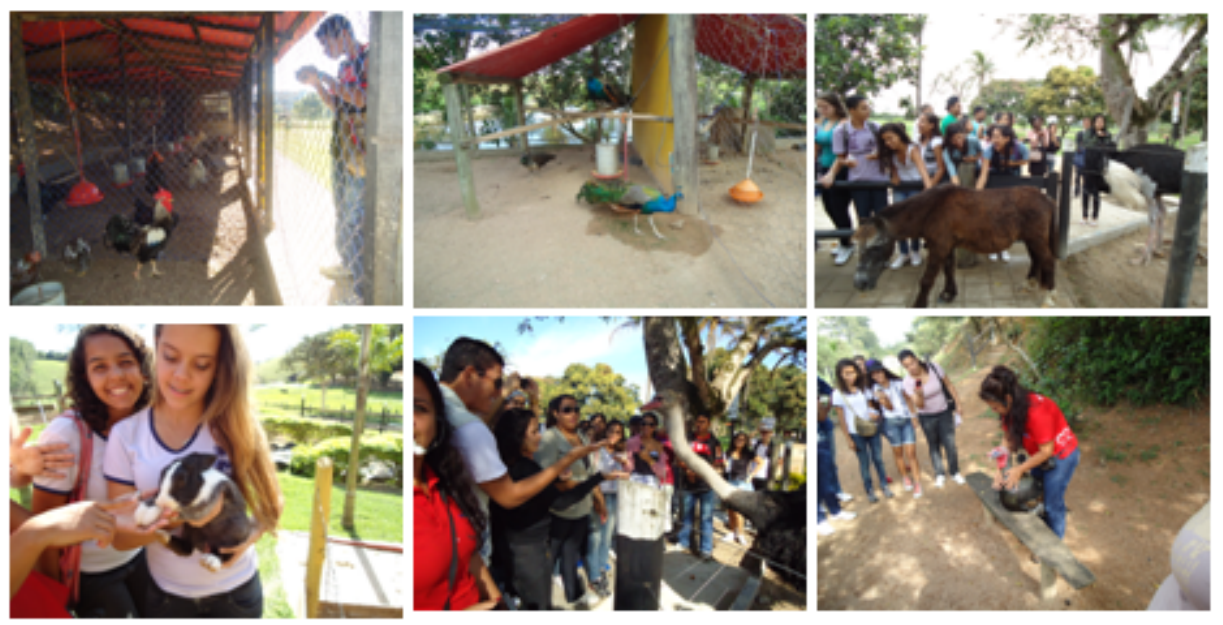

Fonte: Fotografias do arquivo pessoal dos autores. 
Figura 4: Agroturismo: painel fotográfico/tirolesa/pula-pula/bicicleta-aquática, caiaque e pedalinho/jogos/trilha na Mata Atlântica.
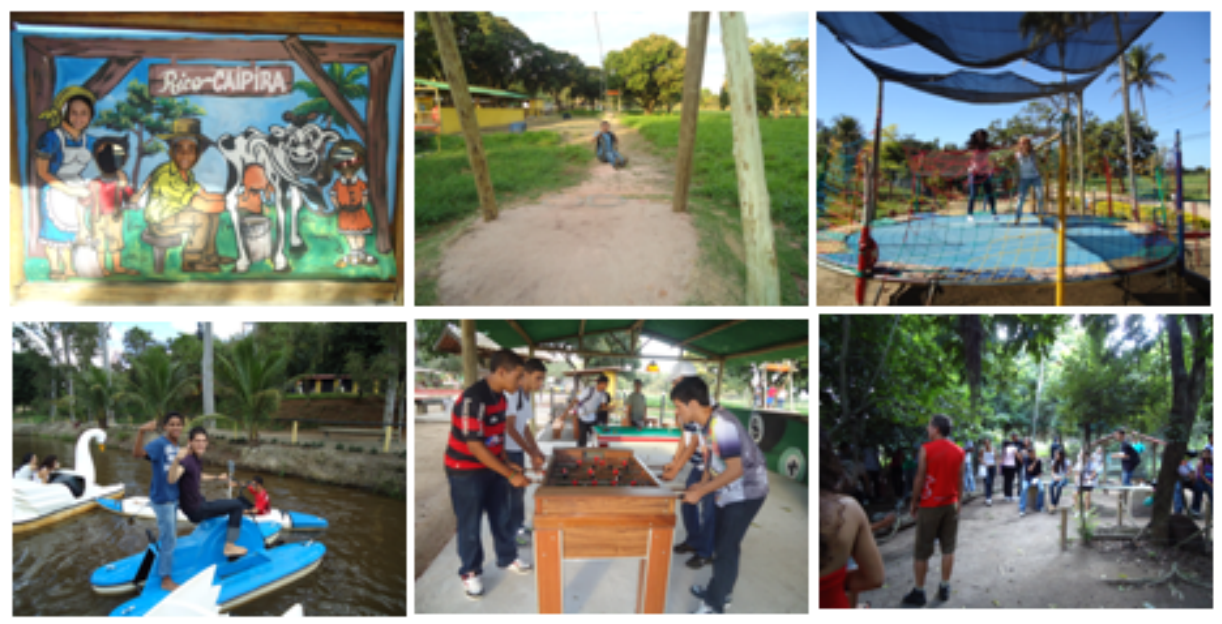

Fonte: Fotografias do arquivo pessoal dos autores.

Os gráficos 1 e 2 apresentam os percentuais de participação dos educandos em cada turma, vale ressaltar, que cada educando custeou seus gastos (transporte, entrada e lanche) o que pode ter sido um fator limitador de adesão à essa atividade.

Gráficos 1: Participação dos educandos nas aulas de campo.

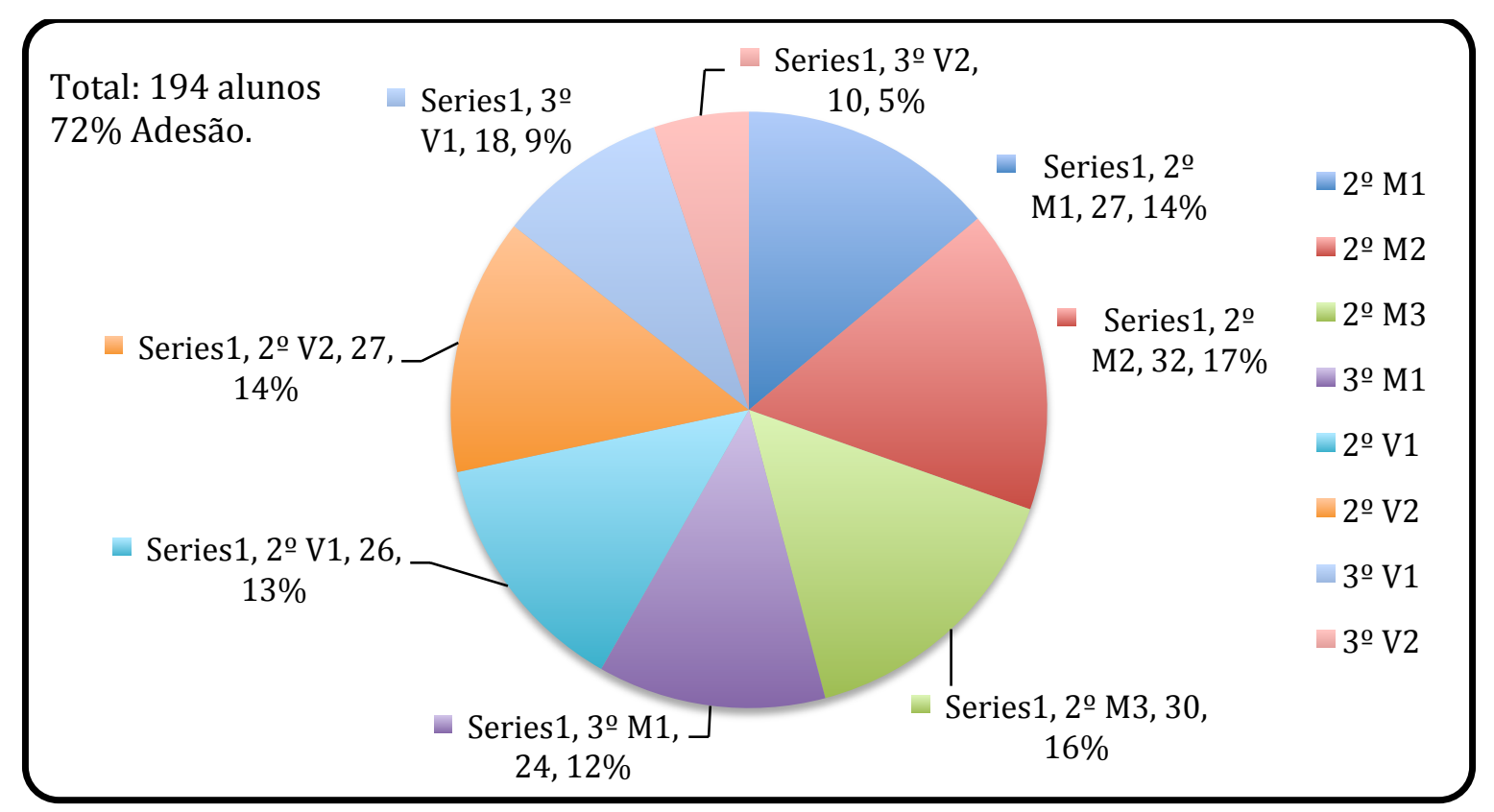

Fonte: Dados da pesquisa. 
Gráfico 2: Alunos que não participaram da aula de campo.

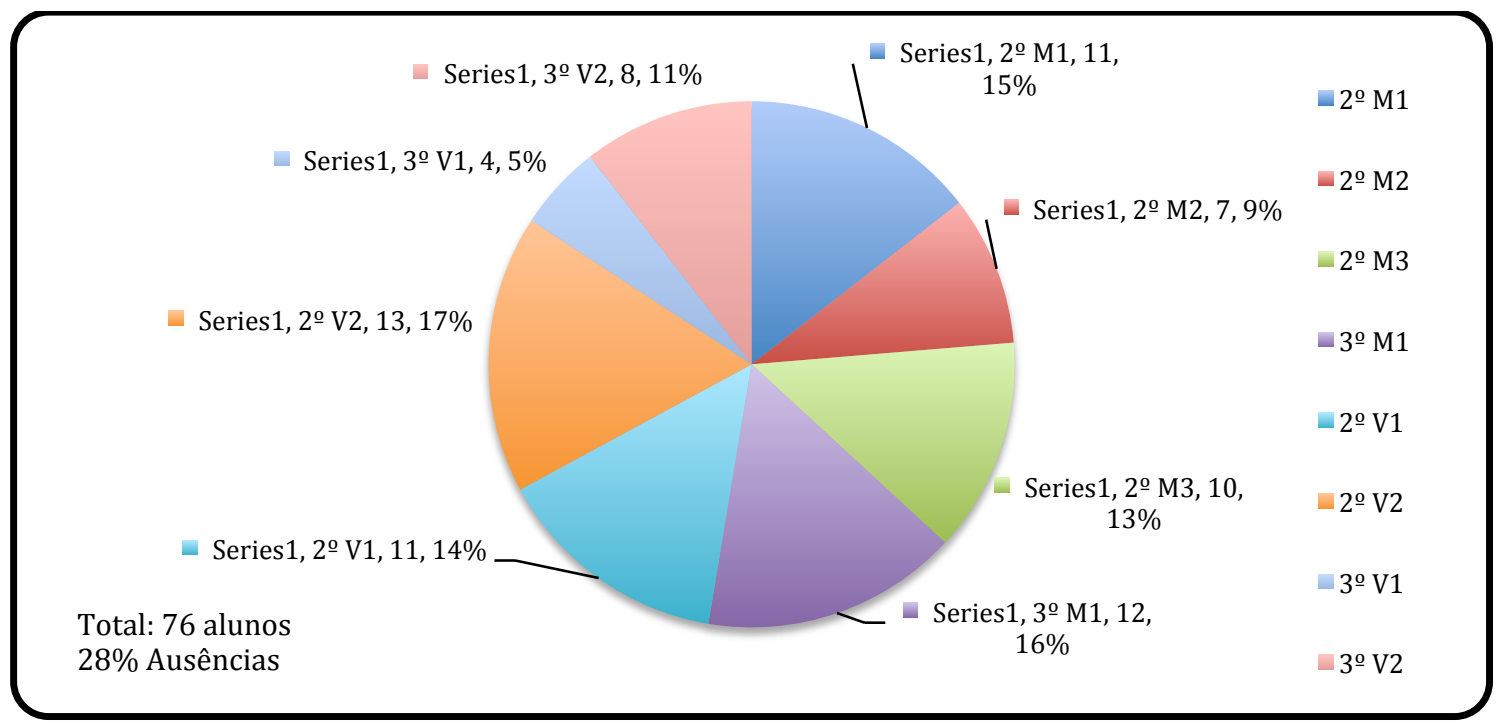

Fonte: Dados da pesquisa.

\section{CONSIDERAÇÕES FINAIS}

As pesquisas contribuíram de forma significativa para a construção do conhecimento. Apesar de, neste artigo, apresentarmos apenas as contribuições da Geografia para o desenvolvimento desta sequência didática, a abordagem dos temas agroindústria e agroturismo nas aulas de História e Sociologia foram de fundamental importância para a compreensão da evolução dos meios de produção e de organização social ao longo do tempo histórico, para a articulação dos conhecimentos e para a aprendizagem significativa dos conteúdos que permeiam estas disciplinas. 0 momento mais esperado pelos educandos foi a aula de campo. É como se ela fosse à solução para todas as problemáticas levantadas nas aulas precedentes. Todos os alunos e professores que participaram das aulas de campo saíram com mais perguntas do que respostas. Foi então, que percebemos que estávamos mais preparados para aprender a aprender, pois os problemas mudam, mas a maneira que buscamos para resolve-los já tínhamos um caminho, que não é único, nem o melhor, mas um bom caminho.

As sequências didáticas, a metodologia da aprendizagem baseada em problemas, os três momentos pedagógicos, as aulas de campo, as pesquisas, discussões e trocas de experiências são práticas educativas que podem e devem estar mais presentes nas aulas de todas as disciplinas do Ensino Médio das escolas públicas estaduais de todo país. Os processos 
avaliativos propostos neste trabalho permitiram uma liberdade de apresentação do conhecimento adquirido de forma clara e concisa. Os textos dos grupos e os relatórios fotográficos dão um panorama do que são e como se organizam as agroindústrias e o agroturismo capixaba.

\section{AGRADECIMENTOS}

Os autores agradecem a equipe pedagógica da EEEM Irmã Dulce Lopes Ponte e aos proprietários da Fazenda Rico Caipira Claudete Zampier da Fonseca e Ricardo Sobreiro Nunes.

\section{REFERÊNCIAS}

DElizoICOV, Demétrio; ANGOTTI, José André; PERnAMBUCO, Marta Maria. Ensino de ciências: fundamentos e métodos. 3aㅡ Ed. São Paulo: Cortez, 2009.

FREIRE, Paulo. Pedagogia da autonomia. Saberes necessários à prática educativa. Coleção Leitura, São Paulo: Paz e Terra, 1996.

MALHEIRO, João Manoel da Silva; DINIZ, Cristowam Wanderley Picanço. Aprendizagem Baseada em Problemas no Ensino de Ciências: mudando atitudes de alunos e professores. AMAZÔNIA - Revista de Educação em Ciências e Matemáticas V. 4 - n. 7 - jul. 2007/dez. 2007, V. 4 - n. 8 - jan 2008/jun. 2008.

MORIN, Edgar; ALMEIDA, Maria da Conceição de; CARVALHO, Edgard de Assis, (orgs.). Educação e Complexidade: Os Sete Saberes e outros ensaios. 3ํㅡㄹ. São Paulo: Cortez, 2005. PONTUSCHKA, Nídia Nacib; PAGANELLI, Tomoko Iyda; CACETE, Núria Hanglei. Para Ensinar e Aprender Geografia. 3aㅗ Ed. São Paulo: Cortez, 2009.

TERRA, Lygia; ARAÚJO, Regina; GUIMARÃES, Raul Borges. Conexões: Estudos de Geografia Geral e do Brasil. 1a Ed. - São Paulo: Moderna, 2010. Volumes 2 e 3.

ZABALA, Antoni. A prática educativa: como ensinar. Porto Alegre: Artmed, 1998. 